\title{
On the necessity of essence
}

\author{
Gaétan Bovey ${ }^{1}$
}

Accepted: 28 October 2021/Published online: 28 January 2022

(C) The Author(s) 2022

\begin{abstract}
In the present inquiry, I defend the claim that the thesis that essence is the source of all (metaphysical) necessity is compromised. I argue that, on pain of circularity, essentialists cannot successfully account for the necessity of essences. In response to the difficulties I raise, I discuss potential solutions on behalf of essentialists and explain why I find none of them compelling. My conclusion on the matter is that the best essentialists can hope for is a view where the necessity of essences is left unexplained (by essences).
\end{abstract}

Keywords Essence $\cdot$ Circular explanations $\cdot$ Metaphysical explanation $\cdot$ Modality $\cdot$ Necessity $\cdot$ Source of necessity

\section{Introduction}

The tenet of Finean essentialism (Fine, 1994) is that essence is the source of all (metaphysical) necessity. ${ }^{1}$ According to this theory, there is an explanation of necessity in terms of essence: if $\square p$, then $\square$ p because some entity is essentially such that $p$. Yet, despite its tremendous influence over the past decades, Finean essentialism has recently been the target of several criticisms that fall into three (non-exhaustive) categories.

First, it is argued that an explanatory gap is felt between essence and necessity (cf., Casullo, 2020; Leech forth.; Mackie, 2020; Noonan, 2019; Romero, 2019). This challenge targets the intelligibility of the sourcehood thesis: it amounts to an

\footnotetext{
$\overline{1}$ Hereafter, I will use 'essentialism' to refer to Finean essentialism.

Gaétan Bovey

gaetan.bovey@uni-tuebingen.de

1 University of Tübingen Philosophisches Seminar, Bursagasse 1, 72070 Tübingen, Germany
} 
explanatory demand of how and why essence gives rise to necessity. ${ }^{2}$ Second, the essentialist theory of necessity is challenged on the grounds that it is incompatible with other views and principles. In particular, Ditter (2020) and Teitel (2019) argue that Fine's (1994) framework is in tension with contingentism and the idea that metaphysical necessity's modal logic obeys the S5 set of axioms. ${ }^{3}$ Third, some objections target the extensional adequacy of the theory. Wildman (2021), for instance, provides a series of counterexamples to the effect that some necessity-facts escape the explanatory scope of essences.

In the present inquiry, I want to bring a fourth difficulty against essentialism. My goal is to argue that, with plausible assumptions and principles, essentialism cannot account for the necessity of essences, because such explanations are compelled to be viciously circular. If I am right, my arguments will considerably reinforce the idea that not all necessities can be explained in terms of essence, and that essentialism must undergo substantial revisions to uphold its main tenet.

The plan is as follows. In Sect. 2, I set the stage for the main discussion with a characterization of the sourcehood thesis and a principle according to which essences are necessarily true. Next, I introduce a structure of explanations that will be the main point of discussion in the remaining sections. In Sect. 3, I discuss difficulties that the sourcehood thesis face, and I explain how essentialists can overcome them. In Sect. 4, I focus on the nature of the essence-facts involved in explanations of necessities, and I explain how these essences are explanatorily connected with one another. In Sect. 5, I defend a principle that bridges explanations of necessity with explanations of truth, and I put forward the main circularity objection against explanations of the necessity of essences in terms of essence. In Sects. 6 and 7, I outline a series of solutions to the difficulties raised in the main discussion, and I argue that none of them is compelling nor satisfactory. In Sect. 8, I conclude by briefly presenting my own take on these issues.

\section{The necessity of essences}

The first step of the present investigation is to characterize the sourcehood thesis:

Source if $\square p$, then $\square p$ because $\exists x(\mathrm{E}(x) p){ }^{4}$

Read: if it is metaphysically necessary that $p$, then this is so because there is some $x$ such that it is true in virtue of the nature of $x$ that $p$ (or, equivalently, such that $x$ is essentially such that $p$ ). Two important remarks are in order. First, the propositional variable ' $p$ ' is construed as being universally quantified, so as to capture the idea that essence is the source of all metaphysical necessities. Second, I read the 'because' locution as denoting metaphysical explanation. What I mean by that term is a non-

\footnotetext{
2 This explanation can be epistemological or metaphysical. Cf., Correia and Skiles (2020) and Wallner and Vaidya (2020) for a discussion.

3 See Werner (2020) for a reply.

${ }^{4}$ For the scope of this discussion, I will solely focus on explanations of necessity that appeal to the nature of a single entity. Note that some necessities are true in virtue of the nature of a plurality of entities-e.g., cases of numerical distinctness.
} 
causal form of explanation that obeys priority and dependence constraints. ${ }^{5}$ With respect to the essentialist framework, this means that essence is metaphysically prior to necessity, and that the latter depends on the former. I also assume that metaphysical explanation possesses the following properties: asymmetry, irreflexivity, and transitivity. Importantly, my discussion is primarily tailored around the assumption that 'metaphysical explanation' is an 'umbrella'-term under which all specific kinds of metaphysical explanation-e.g., grounding, can be unified. I will flag in due time whether some of my arguments rely on a particular kind of metaphysical explanation and, in Sect. 6, I will discuss the option of distinguishing between different kinds of explanation in order to explain how some difficulties might be overcome.

Next, among the philosophers who have followed Fine's footsteps, there is a conjecture according to which essence-truths are metaphysically necessary (cf. Hale, 2013, 2018; Lowe, 2012; Van Cleve, 2018; Wallner, 2019). ${ }^{6}$ For, it would be odd to say that essence-truths could have failed to obtain or that the nature of, say, Socrates could have been different. I contend that the necessity of essence-truths is fairly uncontroversial, and I will not challenge this claim in what follows. In order to systematize my explanations, I capture the idea that every essence-truth is necessary with the following principle ('Necessity of Essence'):

NE $\mathrm{E}(x) p \supset \square \mathrm{E}(x) p$.

Since Source holds for all metaphysical necessities and since, given NE, essences are metaphysically necessary, there must be an explanation of the necessity of essences in terms of essence. More precisely, if $\square \mathrm{E}(x) p$, then there is some $y$, such that $\mathrm{E}(y) \mathrm{E}(x) p$.

There are two possibilities: either $y=x$ or $y \neq x$. The former option appeals to an iterated essence with bearer identity: ' $\mathrm{E}(x) \mathrm{E}(x) \mathrm{p}$ '. For instance, the essence-truth 'Socrates is essentially human' belongs to Socrates's very own essence. The latter option, however, is trickier since it amounts to appeal to an iterated essence without bearer identity: ' $\mathrm{E}(y) \mathrm{E}(x) p$ '. This requires an investigation on its own to find out which (if any) entity is such that it is essential to it that it is essential that Socrates is human (to continue with the same example). I will start my investigation by focusing on iterated essences with bearer identity to illustrate my points. Discussing this option first will allow us to have a better understanding of what is at stake to explain the necessity of essences as well as identifying which challenges essentialists face. I will turn to iterated essences without bearer identity in Sect. $7 .^{7}$

\footnotetext{
5 See Maurin (2019) for the general notion of metaphysical explanation, as well as the dependency constraint.

${ }^{6}$ It is indeed a conjecture since there is not-to my knowledge-a successful argument to the effect that essences are necessary. One attempt is made by Hale (2013), but it presumably fails as Romero (2019) and Leech (2020) argue. See Wallner and Vaidya (2020) for a reply. However, it is possible to prove the necessity of essence if one opts for Correia \& Skiles's (2019) 'generalized-identity' essentialism, but I will not discuss this view here. See Leech (2020) for a detailed discussion of the proof in question.

7 Glazier (2017) provides arguments to the effect that we can never have essence-truths of the type ' $\mathrm{E}(y)$ $\mathrm{E}(x) p$ ' (where $y=x$ or $y \neq x$ ). However, I will ignore this for the sake of the argument and return to it later on. So far, the point of the discussion is to introduce how essentialists can provide systematic explanations of the necessity of essences.
} 
With the assumption that $y=x$, Source and NE are jointly sufficient to generate the following structure ${ }^{8}$ :

\section{Structure 1 (S1)}

4. $[\mathrm{E}(x) \ldots \mathrm{E}(x) p]<[\square \mathrm{E}(x) \ldots \mathrm{E}(x) p]$;

3. $[\mathrm{E}(x) \mathrm{E}(x) \mathrm{E}(x) p]<[\square \mathrm{E}(x) \mathrm{E}(x) p]$;

2. $[\mathrm{E}(x) \mathrm{E}(x) p]<[\square \mathrm{E}(x) p]$;

1. $[\mathrm{E}(x) p]<[\square p]$.

(' $<$ ' denotes metaphysical explanation.) The generation of S1 starts with the explanation of one necessity in terms of an essence truth (line 1), and given NE, that essentialist truth is in turn necessary; per Source, that necessity is explained in terms of an iterated essence truth (line 2), which is in turn necessary, and this process repeats itself ad infinitum.

The way $\mathbf{S 1}$ is structured prompts the question of whether it is-in some way or another-viciously circular and/or regressive. Reasons to think that this is the case greatly depend on whether there are-in addition to explanations of necessity in terms of essence-explanations among necessities and/or among essences, respectively. For instance, $\mathbf{S 1}$ would be viciously circular if some facts eventually explained themselves, and viciously regressive if the success of some explanations depended on infinitely many steps. ${ }^{9}$ My goal in the following Sect. 3 is to provide detailed discussions of these issues, as well as important points of clarification. Doing so will help determine whether $\mathbf{S 1}$ involves substantial difficulties of some kind.

\section{First assessment of S1: necessities}

Begin with necessities. Prima facie, there is little (if any) reason to think that an explanatory connection holds among necessities in S1 (i.e., among the facts on the right hand side in S1), since if Source is true, then each of these necessities is explained by a corresponding essence truth. That is to say, at each particular line (1, 2, etc.) in $\mathbf{S 1}$ an explanatory task is achieved, full stop. However, there are (at least) two reasons to think that the necessity of the essences in $\mathbf{S 1}$ plays a substantial role in explaining other necessities. Let us now consider why one might think so.

Blackburn (1986) propounds a dilemma against any (realist) account of the source of necessity: either the source is contingent or it is necessary. For the scope of the present investigation, I commit to Hale's argument $(2013, \S 5.4)$ according to which metaphysical necessity cannot be based on any form of contingency on pain of being ultimately undermined. ${ }^{10}$ Hence, the only viable option is to say that the

\footnotetext{
${ }_{8}$ Variants of this structure can be found explicitly in the works of Hale (2018), Van Cleve (2018), and Wallner (2019).

9 Let me stress that we should not think of essentialist truths in S1 as entities-e.g., as the essence of $x$, the essence of the essence of $x$, etc. For, as Lowe explains, this construal leads to an infinite regress that, "at worst, would be vicious and, at best, would appear to make all knowledge of essence impossible for finite minds like ours" (2008: 38-39).

${ }^{10}$ See also Van Cleve $(1999,2018)$ for arguments to that effect.
} 
source of necessity is itself necessary. On this picture, the explanation of an arbitrary necessary-truth takes the form ' $\square A$ because $\square B$ '. And as Blackburn explains, "there is no problem about the form of the explanation, for one necessity can well explain another", but there is a "bad residual "must" (1986: 53). This rich passage highlights two difficulties. First, an explanation of why $B$ is necessary is owed and, consequently, we have failed to identify what the source of necessity is; the dilemma moves to the explanans of $\square B$, and we are off a regress. Second, the necessity of $B$ is, according to Blackburn, what explains $\square A$ : the fact that $B$ transmits its necessity to $A$ is what fully accounts for the success of the explanation (Hale, 2013). With respect to essentialism, this means that essences explain necessity insofar as-by 'default' (i.e., because NE holds)— they must be necessary. So if this reasoning is sound, it follows that there is an infinite downwards chains of explanations among necessities on the right hand side of S1, and that each necessity ultimately depends on infinitely many necessities, which renders the structure viciously regressive. ${ }^{11}$ The other problem is that Source cannot be true on that picture and, consequently, that the source of necessity can never be located, as predicted by Blackburn. Let me stress that the necessity horn of Blackburn's dilemma is importantly different from $\mathbf{N E}$ according to which essences are necessary independently from considerations regarding their explanatory role as the source of necessity. As we have seen, this does not jeopardize Source: under such a view, a structure like $\mathbf{S 1}$ can be generated.

Note also the following: if what explains why ' $p$ ' is necessary is not ' $\mathrm{E}(x) p$ ' but only ' $\square \mathrm{E}(x) p$ ', then, by the same token, ' $\mathrm{E}(x) \mathrm{E}(x) p$ ' is not the explanans of the necessity of ' $\mathrm{E}(x) p$ '. In this case, I contend that appealing to ' $\square \mathrm{E}(x) \mathrm{E}(x) p$ ' in order to explain ' $\square \mathrm{E}(x) p$ ' is unwarranted, because we relied on iterated essences solely on the grounds that essences-and not their modal status-were explanatory relevant. In brief, if what has just been said is true, then the resulting picture would be one where brute necessities-essences-explain derivative necessities: $[\square \mathrm{E}(x) p]<[\square p]$. Hence, essentialism may not be compatible with there being an infinite downwards chains of necessities, because the necessity of essences might simply be brute if the necessity horn of Blackburn's dilemma is fatal.

That being said, the necessity horn of Blackburn's dilemma can be resisted. For, Blackburn assumes that if the source of necessity is itself necessary, then that necessity is eo ipso an explanatory condition (or prerequisite) for explanations of necessity. In response, essentialists can say that the relation between a given source and the necessity of that source is merely an entailment (i.e., if $A$ is the source of necessity, then $\square A$ ), and that this does not, in and of itself, entail that the source's necessity plays an explanatory role with respect to the explanandum. Thus, the explanatory role of a given source can be vindicated independently of its modal status and, to that effect, essentialists can safely uphold NE (which is an instance of the above entailment between a source and its necessity). In sum, even if

\footnotetext{
${ }^{11}$ By taking a close look at $\mathbf{S 1}$, this means that each necessity is explained by/dependent upon the necessity directly above it.
} 
essentialists sit on the necessity horn of Blackburn's dilemma, that does not mean that the necessity of essences must play an explanatory role in explaining necessity.

However, even if what has just been said is true, essentialists run into another difficulty. Some philosophers have raised concerns-which are cognate to the explanatory gap problem (cf. Sect. 1 for the references) - against the idea that necessity can be successfully accounted for in terms of essence. Their thought is that, as opposed to what essentialists claim, essence-truths simpliciter are devoid of any capacity to explain necessity. According to Romero, " $a$ being essentially $F$ does not by itself explain why is it that $a$ is necessarily $F$ " (2018: 7). Rather, explanations of necessity in terms of essence get off the ground insofar as the necessity of essences is assumed. To be precise, that means that necessities in S1 are either explained by essences together with the necessity of essences or solely by the fact that essences are necessary. ${ }^{12}$ If the former, then the problem is that $\mathbf{S 1}$ involves an infinite downwards chains of explanations of necessities. This is viciously regressive because every single necessity (partly) depends on infinitely many necessities. If, on the other hand, the necessity of essence is both necessary and sufficient to explain necessity, then the difficulties tied to the necessity horn of Blackburn's dilemma arise: the source of necessity can never be located and there is an infinite regress.

Wallner and Vaidya (2020) offer a thorough discussion of this problem. In order to understand their view, let me stress that these authors endorse the thesis that all necessities are grounded in essence, and I will assume this claim while assessing their arguments below. Following Hale (2013), Wallner and Vaidya claim that essences provide non-transmissive (grounding) explanations of necessities-i.e., even though essences are necessary, this modal status is not what explains necessity; rather it is the truth of essences that does the 'heavy lifting' towards the explanandum. Next, Wallner and Vaidya concede to their opponents "that there is justification for the claim that it is impossible for entirely non-modal essences to explain (or ground) necessity" (2020: 23). However, they argue that it does not follow that the necessity of essence is what explains necessity; rather the necessity of essence plays a distinctive role in explaining why essences can explain necessity (Ibid.: 14). In other words, it is because essences are necessary that they have the capacity to explain necessity. Schematically: $[\square \mathrm{E}(x) p]<[\mathrm{E}(x) p<\square p]$, and it does not follow that $[\square \mathrm{E}(x) p]<[\square p] .{ }^{13}$ This strategy allows essentialists to defend that the fact that essences are (and, given all what as been said so far, must be) necessary does not jeopardize the claim that essence is the source of necessity-and the above difficulty can be successfully barred.

However, as promising as this strategy looks, it faces one difficulty: Wallner and Vaidya can presumably not uphold the claim that all necessities are grounded in essence. The reason is that if the necessity of ' $\mathrm{E}(x) p$ ' must be secured (grounded) in

\footnotetext{
${ }^{12}$ I make this distinction clear because it is not always made explicit what the objectors have in mind when they say that the necessity of essences plays an explanatory role.

13 It is unclear to me what Wallner and Vaidya's view is regarding the explanatory relation between [ $\square \mathrm{E}$ ( $x) p]$ and $[\mathrm{E}(x) p<\square p]$. Presumably, it is grounding and this might raise several questions regarding metagrounding-i.e., what grounds the grounding facts.
} 
order for ' $\mathrm{E}(x) p$ ' to have the capacity to bring forth ' $\square p$ ', then they are off to a vicious regress. To establish the necessity of ' $\mathrm{E}(x) p$ ' - which guarantees that ' $\mathrm{E}(x) p$ ' can explain ' $\square p$ ' - they would need to appeal to ' $\mathrm{E}(x) \mathrm{E}(x) p$ '. Yet, ' $\mathrm{E}(x) \mathrm{E}(x) p$ ' does not possess the capacity to explain the necessity of ' $\mathrm{E}(x) p$ ' unless its own necessity has been secured, and so they would need to appeal to ' $\mathrm{E}(x) \mathrm{E}(x) \mathrm{E}(x) p$ ', and so on $a d$ infinitum. ${ }^{14}$ In any case, the regress is vicious, because there is an explanatory failure at each step (Bliss, 2013). ${ }^{15}$ Of course, a straightforward way out of this problem is to take the necessity of essence as brutelfundamental, but that undermines Source. $^{16}$

Importantly, it is not my goal to discuss whether essentialists actually face the problem of the explanatory power of essences just detailed. Rather, my point is more modest: it merely consists in saying that if one wants to defend Source and if one thinks that there is a genuine issue in the sense that essences simpliciter cannot give rise to necessity, then opting for Wallner and Vaidya's strategy to counter this difficulty triggers the vicious regress just identified. In what follows, I will assume that essences simpliciter can explain necessity, and I will flag in due time if the explanatory role of the necessity of essence may be relevant. The lesson to be drawn from this section is that the necessity horn of Blackburn's dilemma does not need to have the dire consequence it was supposed to have: the mere fact that being the source of necessity entails that this source is itself necessary (i.e., the necessity horn) does not, in and of itself, entail that the necessity of the source plays an explanatory role in explaining other necessities.

\section{Second assessment of S1: essences}

Let us now turn to the question of whether explanatory connections hold among essences. Here, I contend that two options must be rejected: $(\alpha)$ no essence is explained by any other essence in $\mathbf{S 1}$, and $(\beta)$ every essence in $\mathbf{S 1}$ is explained by the essence directly above it-e.g., ' $\mathrm{E}(x) \mathrm{E}(x) p$ ' is explained by ' $\mathrm{E}(x) \mathrm{E}(x) \mathrm{E}(x) p$ '. In order to explain why neither of these options is sustainable, a proper investigation regarding the 'nature' of the essences in S1 is required, as well as important considerations about the direction of explanations, to which I now turn.

The first important point is Fine's distinction between the notions of constitutive and consequential essence $(1995)^{17}$ : the constitutive essence of an entity, $x$, contains

\footnotetext{
${ }^{14}$ Note that the same is true with iterated essences without bearer identity: the necessity of ' $\mathrm{E}(y) \mathrm{E}(x) p$ ' would have to be secured, and so appeal to some entity, $z$, such that $z \neq y$ would have to be made, etc.

15 Presumably, even if the explanation at stake is not grounding, the problem might also arise in terms of dependence: the success of explaining ' $\square p$ ' in terms of ' $\mathrm{E}(x) p$ ' would depend on the completion of infinitely many explanatory tasks.

${ }^{16}$ I think that this is what Wallner and Vaidya might be committed to since they think that there is no substantive answer to the question of why essences are necessary (2020: 21).

17 Fine offers several ways to understand the distinction, sometimes taking one of the two notions as definable in terms of the other or vice-versa. Here, however, I take no stance with such debates and solely rely on an intuitive way to spell out the distinction.
} 
the propositions that are directly definitive of $x$, while its consequential essence contains the propositions that are obtained when the constitutive notion is closed under logical consequence. For instance, it is constitutively essential to Socrates that he is human, but consequentially essential to him that he is human or a fish. Focusing on $\mathbf{S 1}$, ' $\mathrm{E}(x) p$ ' is a claim of constitutive essence since ' $p$ ' is directly definitive of $x$-i.e., about $x$. However, iterated essences with bearer identity such as ' $\mathrm{E}(x) \mathrm{E}(x) p$ ' are not of the constitutive kind. For one thing, this claim cannot be directly definitive of $x$ since it speaks about the essence of $x$ and not about $x$. For another, Fine developed a Logic of Essence that governs the consequential notion of essence. In this work, Fine proves the following theorem: $\mathrm{E}(x) p \supset \mathrm{E}(x) \mathrm{E}(x) p(1995$ : 255). Thus, ' $\mathrm{E}(x) \mathrm{E}(x) p$ ' is a claim that derives from ' $\mathrm{E}(x) p$ ' and that belongs to the consequential essence of $x$ (and the same is true of all the other iterated essences in S1).

Given this important distinction, it is pretty clear that not all essences in S1 enjoy the same metaphysical status-for instance, as if each of them were entirely unrelated to the others. To pump intuitions, structures like S1 are not, as it were, 'discovered'. Rather, they are generated (as explained in Sect. 2). The crucial and decisive step in this process, then, is when appeal to ' $\mathrm{E}(x) \mathrm{E}(x) p$ ' is made to explain ' $\square \mathrm{E}(x) p$ '. To that effect, I contend that this iterated essence finds its source in-and is thereby metaphysically explained by- $\mathrm{E}(x) p{ }^{,}{ }^{18}$ Importantly, I am not saying that because ' $\mathrm{E}(x) p$ ' is the logical source of ' $\mathrm{E}(x) \mathrm{E}(x) p$ ', it is therefore the case that ' $\mathrm{E}(x) p$ ' is also the metaphysical source of ' $\mathrm{E}(x) \mathrm{E}(x) p$ '. Both claims are true, but they are true independently from one another and they overlap in the present case. This is similar to the situation where ' $A$ ' and ' $B$ ' are not only the logical source of the conjunction 'A and B', but also the metaphysical ground of [A and B]. The point, then, is that even if there is an entailment at stake, as Fine's theorem establishes, it is also the case that, metaphysically speaking, iterated essences are generated from a constitutive (and non-iterated) essence: ' $\mathrm{E}(x) p$ ' is prior to ' $\mathrm{E}(x) \mathrm{E}(x) p$ ', and the latter depends on the former. In fact, it would be a rather strange metaphysical framework if infinitely many essences like the ones in $\mathbf{S 1}$ were independently 'wandering' out there, and if, despite their structural similarity, there were no explanatory way to connect them with one another. ${ }^{19}$ We can clarify the explanatory connection at stake with the terminology of Correia (2012): consequential essences are derivative, because they admit of further explanation in essentialist terms (i.e., it is because ' $\mathrm{E}$ $(x) p$ ' that ' $\mathrm{E}(x) \mathrm{E}(x) p$ '). By contrast, even if ' $\mathrm{E}(x) p$ ' might admit of some kind of explanation, it is presumably basic in the sense that it is not explained in further essentialist terms - and, for that matter, most certainly not in terms of an essence that derives from it.

As soon as the idea that essences in S1 constitute an upwards chains of explanations is fully appreciated (i.e., a chains that proceeds from ' $\mathrm{E}(x) p$ ' to ' $\mathrm{E}(x) \mathrm{E}$ $(x) p$ ', etc.), options $(\alpha)$ and $(\beta)$ break down. So even if, so far, the question of what

\footnotetext{
18 Dasgupta (2014: 591) holds that claims of consequential essence are grounded in claims of constitutive essence. A similar reasoning applies to the so called 'truth-regress'.

19 Moreover, if, say, God obliterated ' $\mathrm{E}(x) p$ ', I contend that the collapse of all the iterated essences above ' $\mathrm{E}(x) p$ ' in $\mathbf{S 1}$ would ensue.
} 
explains ' $\mathrm{E}(x) p$ ' is left unanswered, iterated essences in $\mathbf{S 1}$ admit of an explanation. Consequently, $(\alpha)$ is false. And since the direction of explanations among essences proceeds upwards, it can hardly be maintained that $(\beta)$ is true on pain of vicious circularity: since ' $\mathrm{E}(x) p$ ' explains ' $\mathrm{E}(x) \mathrm{E}(x) p$ ' there would be, in turn an explanation of the former claim in terms of the latter, which violates both the asymmetry and irreflexivity of explanation. ${ }^{20}$ (Also, a constitutive essence would be both prior and posterior to itself, as well as dependent on something that depends upon it. This is untenable.) Furthermore, such a downwards chains of explanations would also go against the plausible idea that explanations flow from the simpler facts to the more complex ones, and that there are no infinite descending chains of explanation. ${ }^{21}$

The way essences are structured in $\mathbf{S 1}$ has important consequences for the thesis according to which essence is the source of all metaphysical necessities, as I will now explain.

\section{S1 and circular explanations}

Let us consider ' $\mathrm{E}(x) p$ ': this essence does not only provide an explanation of ' $\square p$ ' but also of ' $\mathrm{E}(x) \mathrm{E}(x) p$ '. In accordance with the strategy considered so far, this latter iterated essence is needed to explain ' $\square \mathrm{E}(x) p$ ' (which, again, is directly obtained since NE is true of ' $\mathrm{E}(x) p^{\prime}$ ') and to uphold Source. Hence, we arrive at the following schematic instance of how explanations of the necessity of essences are structured in S1:

$[\mathrm{E}(x) p]<[\mathrm{E}(x) \mathrm{E}(x) p],[\mathrm{E}(x) \mathrm{E}(x) p]<[\square \mathrm{E}(x) p] ;$

etc.

I find such explanations suspicious, because ' $\mathrm{E}(x) \mathrm{E}(x) p$ ' is explained by ' $\mathrm{E}(x) p$ ' and, in turn, ' $\mathrm{E}(x) \mathrm{E}(x) \mathrm{p}$ ' explains something that pertains to ' $\mathrm{E}(x) p$ ': its modal status. I think that essentialists are getting dangerously close to a circularity. And, in fact, there is only one step to take to reach such a result.

The reason is that, quite independently from what Fine's theory of essence has to say about explanations of necessity per se, the connection between a given essence and its prejacent proposition is considered to be an explanatory one. ${ }^{22}$ That is, if ' $\mathrm{E}$ $(x) p$ ', then ' $p$ ' is explained by ' $\mathrm{E}(x) p$ '. To illustrate, Socrates is human because

\footnotetext{
${ }^{20}$ Worries in connection to option $(\beta)$ seem to find their source in a principle advocated by Rosen (2010: 119): if $\mathrm{E}(x) p$, then $[p]$ is grounded in $[\mathrm{E}(x) p]$. However, if true, this principle can presumably not be applied unrestrictedly. For, that would be viciously regressive: $[\mathrm{E}(x) p]$ would depend on infinitely many essence-facts. See also Dasgupta (2014) and Van Cleve (2018) for a discussion and related difficulties that Rosen's principle triggers.

21 Cf., Rabin and Rabern (2016), and Van Cleve 2018) for similar points.

22 As Glazier puts it "it can hardly be denied that ' $t$ is essentially such that $A$ ' provides a metaphysical kind of explanation of $A$ " (2017: 2874). However, he disagrees with Rosen (2010) who flirts with the idea that the kind of metaphysical explanation at stake is grounding, as explained in footnote 9.
} 
Socrates is essentially human. ${ }^{23}$ Undoubtedly, such explanations are metaphysical in nature, and when combined with Source, the resulting picture is one where essence does not only support explanations of why a given proposition, $p$, is (metaphysically) necessary, but also of why $p$ is true: there is no 'division of labour' between essence and some other phenomenon. I contend that this is precisely how such explanations are supposed to go. For, it would be strange to think that some phenomenon $\Phi$ is explanatory relevant to $p$ 's (metaphysical) necessity but not to $p$ 's truth. Van Cleve makes a similar point:

If we say with Descartes that the Pythagorean Theorem is necessary only because it was established by God, we should also say that it is true only because it was established by God. To believe otherwise is to attribute to God a queer form of omnipotence that holds sway over truths of the form 'p' but not over truths generally. And similarly in other cases. For example, proponents of the linguistic theory of logical necessity should say (and did say) that necessary truths are true in virtue of meanings. Returning to Kant, if we say that the propositions of geometry owe their necessity to our cognitive constitution, we should also say that they owe their truth to our constitution. (1999: 40)

The rationale behind Van Cleve's examples is that whatever makes something necessary also makes it true.

These observations can be generalized so as to obtain the following principle that I find plausible:

NT If $[A]<[\square B]$, then $[A]<[B] .^{24}$

I contend that NT holds only for metaphysical necessity and what stands for its source. I take no particular stance on whether NT is true for other kinds of necessity and their respective source(s), such as, for instance, normative necessity. Thus, applied to the essentialist framework, NT amounts to say that if an essence explains why a proposition $p$ is necessary, then that same essence explains why $p$ is true. And this should be no surprise: after all, given that essentialists endorse Source, they should have no reason to deny that, given a particular necessity, essences fit the role of the explanans in NT's antecedent. And, to my knowledge, no essentialist denies the explanatory link between a constitutive essence and its prejacent. ${ }^{25}$ Thus, it should pose no problem for essentialists to say that essence plays the role of the explanans in the consequent of NT either. ${ }^{26}$ To illustrate what has just been said,

\footnotetext{
${ }^{23}$ The focus of the question is on Socrates himself. If the question targets being human and why it is predicated of Socrates rather than being a water molecule, then the explanans is presumably not Socrates's essence. Thanks to Thomas Sattig for bringing my attention to this crucial distinction.

${ }^{24}$ The formulation of this principle is inspired by several remarks made by Van Cleve in his (1999) and (2018).

25 Cf. Glazier (2017), Rosen (2010), Vogt (2020), Zylstra (2019).

${ }^{26}$ One might think that NT holds solely on the grounds that it is backed up by transitivity, via an explanation of $B$ in terms of $\square B$-i.e., if $[A]<[\square B] \&[\square B]<[B]$, then $[A]<[B]$. This might be true if what stands for ' $A$ ' is a phenomenon other than essence and if the necessity at stake is not metaphysical (or absolute). In the context of essence, however, even though I do not deny that ' $\square B$ ' entails 'B', I
} 
consider the following essentialist instance of NT: if $[\mathrm{E}(x) p]<[\square p]$, then $[\mathrm{E}(x) p]<$ $[p]$. Note, however, that it may well be the case that, depending on what stands for 'A' in NT, A metaphysically explains B together with some law. For simplicity, I will assume here that if A is substituted for essence in NT, then A fully explains B. This should not substantially affect the following arguments.

Now, NT brings problematic consequences onto $\mathbf{S} 1$ and raises several important questions for the metaphysics of essence. One of the main difficulties is that since [E $(x) p]$ explains $[\mathrm{E}(x) \mathrm{E}(x) p]$ and since, in turn, $[\mathrm{E}(x) \mathrm{E}(x) p]$ explains $[\square \mathrm{E}(x) p]$, it follows by NT that $[\mathrm{E}(x) \mathrm{E}(x) p]$ should also explain $[\mathrm{E}(x) p]$. This constitutes a direct violation of the asymmetry of explanation-i.e., $[\mathrm{E}(x) p]<[\mathrm{E}(x) \mathrm{E}(x) p]$ and $[\mathrm{E}(x) \mathrm{E}(x)$ $p]<[\mathrm{E}(x) p]$. Also, with the assumption that metaphysical explanation is transitive, it follows that $[\mathrm{E}(x) p]$ eventually explains itself, which violates the irreflexivity of explanation. In brief, S1 is structurally problematic since it involves circular explanations. ${ }^{27}$ So something has got to give. As explained in Sect. 4 we have no reason to think that, in $\mathbf{S 1}$, an iterated essence explains a constitutive essence (or, perhaps, an essence being 'simpler' than itself (cf. Van Cleve (2018)). Consequently, since it cannot be the case that $[\mathrm{E}(x) \mathrm{E}(x) p]$ explains $[\mathrm{E}(x) p]$, then, by modus tollens, $[\mathrm{E}(x) \mathrm{E}(x) p]$ does not explain $[\square \mathrm{E}(x) p] .^{28}$

If what has been said so far is true, then we no longer have a structure of essences and necessities like S1, but rather a different explanatory schemata that takes the following form:

2. $[\square \mathrm{E}(x) p]$;

1. $[\mathrm{E}(x) p]<[\square p]$.

On this view, the necessity of ' $\mathrm{E}(x) p$ ' lacks an explanation in terms of essence and Source is false (since not all necessities find their source in essence). In fact, NT neatly establishes that if ' $\mathrm{E}(x) p$ ' lacks an explanation (in terms of essence), then so does its necessity (more on this in the next section). My point, then, is that since we cannot appeal to iterated essences (with bearer identity) to explain the truth of constitutive essences, then, by the same token, we cannot explain their necessity in that way. Given that the appeal to an iterated essence (with bearer identity) involves that such essences derive from and-consequently-are explained by a (corresponding) constitutive essence, there cannot be an explanation of the latter in terms of the former.

\footnotetext{
Footnote 26 continued

contend that NT holds without the help of transitivity. This is because of the intimate connection between an essentialist truth and its prejacent: it is because it is true in virtue of the nature of $x$ that $p$ that $p$ is true, and not because $p$ is necessary that $p$ is true. The latter is merely a 'consequence' of the view.

27 Difficulties also arise in terms of priority and dependence. Eventually, ' $\mathrm{E}(x) \mathrm{E}(x) p$ ' depends upon ' $\mathrm{E}(x)$ $p$ ', but ' $\mathrm{E}(x) p$ ' also depends upon ' $\mathrm{E}(x) \mathrm{E}(x) p$ ' since NT holds. Each fact is therefore prior to the other and, by transitivity, dependent upon and prior to itself.

28 Perhaps, we should be cautious about the kind of metaphysical explanation at stake in these arguments. I will return to this point shortly in (\$5).
} 


\section{Potential solutions on behalf of essentialists}

So far, my arguments have relied on Source, NE, NT, together with the plausible assumption that ' $\mathrm{E}(x) \mathrm{E}(x) p$ ' is metaphysically explained by ' $\mathrm{E}(x) p$ '. In order to block the violations of asymmetry and irreflexivity identified in the previous section, essentialists can reject and/or modify some of these claims. But how? And which ones actually qualify? Source should not be denied because doing so would amount to weaken the explanatory power of the essentialist theory. Of course, one could impose a restriction on Source together with a disjunctive condition on explanations of necessity, but I will appeal to such a strategy — and, more generally, to any kind of modification on Source-should it happen that no other option is available. $^{29}$ With respect to $\mathbf{N E}$, essentialists could reject it on the grounds that essences are purely amodal (i.e., neither necessary nor contingent). But here I must side with Wildman who explains that such a strategy commits one to modal gaps (2018: 8): how can something entirely devoid of any modal status give rise to necessity $?^{30}$ Hence, the difficulties raised by the authors I have mentioned in Sect. 1) will arise if the amodal move is endorsed. Finally, as explained in Sect. 4, we have good reasons to uphold the assumption according to which ' $\mathrm{E}(x) p$ ' provides a metaphysical explanation of ' $\mathrm{E}(x) \mathrm{E}(x) p$ ', and not the other way around. By elimination, then, we are left with NT.

The first thing that comes to mind is that essentialists could simply reject NT on the grounds that since it triggers the substantial difficulties I have raised, it is a sign that it must be false (or, at least, that it does not hold for the essentialist framework). Here, however, I must disagree. For, NT does not compromise the explanatory role of a constitutive essence towards the necessity and the truth of its prejacent: if $[\mathrm{E}(x) p]<[\square p]$, then $[\mathrm{E}(x) p]<[p]$. Instances of such schematic explanations seems perfectly acceptable to me.

The best shot available to essentialists, then, is trying either to clarify how NT can be construed or to modify it, and I will now provide two examples of how this can be done. For the first kind of strategy, one could argue that my views on 'metaphysical explanation' are not fine-grained enough, because identifying which specific kinds of metaphysical explanations are involved in $\mathbf{S 1}$ might be relevant to block my arguments. In particular, essentialists could try to argue that the explanatory relation at stake in the consequent of NT is substantially different from the explanatory relation that holds between constitutive essences and iterated essences. This would amount to argue that even if, say, ' $\mathrm{E}(x) p$ ' $\varphi$-explains ' $\mathrm{E}(x) \mathrm{E}(x)$ $p$ ' and ' $\mathrm{E}(x) \mathrm{E}(x) p$ ' $\psi$-explains ' $\mathrm{E}(x) p$ ', no violations of asymmetry and irreflexivity ensue because $\varphi$-explanations and $\psi$-explanations cannot be chained together.

However, this strategy faces several challenges. To see why, essentialists have to identify what are the specific kinds of metaphysical explanations that can be substituted for $\varphi$ and $\psi$. With respect to the former, grounding seems to be the only

\footnotetext{
${ }^{29}$ Hale (2013) for instance argues that Source should be restricted to necessities that do not prefix an essentialist operator.

30 See also Mackie (2020). Note that with the amodal view it is not possible to rely on Wallner and Vaidya's strategy since no appeal can be made to the necessity of essence to explain how essence have the capacity to explain necessity.
} 
viable option, which means that ' $\mathrm{E}(x) \mathrm{E}(x) p$ ' is grounded in ' $\mathrm{E}(x) p$ ' ${ }^{31}$ And with respect to $\psi$, there are not many candidates to choose from. For obvious reasons, we cannot appeal to grounding and so we have to find another kind of metaphysical explanation that can govern essences and their prejacent. To my knowledge, the only candidate in the literature is Glazier's essentialist explanation - a sui generis kind of metaphysical explanation that takes the following form: " $A$ because $t$ is essentially such that $A$ " (2017: 2873). ${ }^{32}$ The question for essentialists is whether Glazier's essentialist explanations can be chained with grounding. Yet, regardless of a decisive answer on that matter, it will be of no help. For, as Glazier explains, essentialist explanations are only meant to govern the constitutive notion of essence, and they are ultimate-i.e., their explanantia do not admit of an essentialist explanation. This means that if essentialists construe the consequent of NT as involving essentialist explanation, they can only use this principle at the level of $\mathrm{E}(x) p$ in S1. So, since ' $\mathrm{E}(x) p$ ' essentially explains ' $p$ ', it follows by ultimacy that ' $\mathrm{E}(x) p$ ' cannot be essentially explained by ' $\mathrm{E}$ $(x) \mathrm{E}(x) p$ '. Therefore, if ' $\mathrm{E}(x) \mathrm{E}(x) p$ ' does not explain ' $\mathrm{E}(x) p$ ', then, by modus tollens on this essentialist construal of NT, ' $\mathrm{E}(x) \mathrm{E}(x) p$ ' does not explain ' $\square \mathrm{E}(x) p$ '.

Importantly, the success of this strategy depends entirely on there being a specific kind of metaphysical explanation that does not only hold between essences and their prejacent, but that can also not be chained with grounding. ${ }^{33}$ In the absence of such a candidate-explanation that can be substituted for $\psi$, I contend that this strategy is of no help to block the violations of asymmetry and irreflexivity in S1.

The second kind of strategy essentialists can opt for consists in modifying NT. One way to do so is as follow:

NT* if $[A<\square B] \& \neg[B<A]$, then $[A<B]$.

With $\mathbf{N T}^{*}$, essentialists can uphold the idea that iterated essences explain the necessity of other essences. ${ }^{34}$ That is, since the antecedent of NT* will always be false if ' $A$ ' and ' $B$ ' stand for essence-truths, inferences to instances of ' $A<B$ ' are blocked. However, I fear that such a modification rests on purely ad hoc grounds: one would endorse it solely to avoid difficulties that arise at the level of iterated essences in S1. And even if this were not the case, I am inclined to think that whatever the source of necessity is, it should provide explanations uniformly and in accordance with NT-especially if this principle works just fine with constitutive essences and their prejacents. So, to say that ' $\mathrm{E}(x) \mathrm{E}(x) p$ ' is only relevant to the necessity of ' $\mathrm{E}(x) p$ ' strikes me as unwarranted.

Further investigation is required to figure out whether essentialists can bring other kinds modifications upon NT in order to block the violations of asymmetry

\footnotetext{
31 Cf. Dasgupta (2014).

32 See Glazier (2017: §2) for arguments to the effect that essentialist explanation is sui generis and that, therefore, it should not to be conflated with grounding (and other kinds of metaphysical explanations).

33 One might disagree that grounding is the relation at stake between ' $\mathrm{E}(x) p$ ' and ' $\mathrm{E}(x) \mathrm{E}(x) p$ '. To be fair, I do not know what kind of other explanation can be appealed to in this case. But either way, this explanation, $\varphi$, must be such that it cannot be chained with whatever explanation is substituted for $\psi$. In the absence of a better candidate than grounding, I think that my point holds.

34 Thanks to Tobias Wilsch for this suggestion.
} 
and irreflexivity. Here, I merely outlined two strategies and explained why, in my opinion, they fail. I will leave it at that for the time being.

Thus, what emerges from this discussion is that there is a schism within the explanatory framework of essence: on the one hand, NT works just fine with constitutive essences and their prejacent, but, on the other hand, it fails to deliver the expected results at the level of iterated essences (with bearer identity). What kind of conclusion should we draw from this? I contend that just because NT fails at the level of iterated essences (with bearer identity), it is not sufficient to conclude that NT is false. Rather, I think that the proper conclusion to draw is that the necessity of a given essence should not, by all means, be explained by a fact that derives from that very same essence.

So far, I have investigated the idea that what explains the necessity of ' $\mathrm{E}(x) p$ ' is the essence of some $y$, such that $y=x$. I have identified what kind of difficulties follow from this assumption, and I will now pursue my investigation with the assumption that $y \neq x$.

\section{Iterated essences without bearer identity}

In this section, I will try to explain how the necessity (and also the truth) of ' $\mathrm{E}(x) p$ ' might be accounted for if appeal to iterated essences without bearer identity is made. This strategy consists in saying that ' $\mathrm{E}(x) p$ ' owes its necessity to the constitutive essence of some $y$, such that $y \neq x$ : ' $\square \mathrm{E}(x) p$ ' because ' $\mathrm{E}(y) \mathrm{E}(x) p$ '. ${ }^{35}$ But what can $y$ be? It is difficult to find an answer. In his (2017), Glazier argues that there is no entity $y$ such that it is true in virtue of the constitutive essence of $y$ that ' $\mathrm{E}(x) p$ '. Even though Glazier discusses this point to sustain the claim that essentialist explanations are ultimate, I think that it is an important question that essentialists ought to have in mind. Generally speaking, asking whether constitutive essences belong to the essence of some $y$ amounts to ask whether such essences can be explained.

Glazier mentions that $y$ could be Essence itself. (Hereafter, I use the capital letter ' $E$ ' to refer to essence qua essence.) This would mean that constitutive essences of the form ' $\mathrm{E}(x) p$ '- such that $x \neq$ Essence-are essential to Essence. But a few problems immediately arise for this view. All constitutive essence-claims will be essential to Essence: the facts that Socrates is essentially human, that Plato is essentially human, etc. The difficulty is that it does not seem that we are in the business of characterizing what Essence is if we say that Essence is such that Socrates/Plato is essentially human. Intuition suggests that Essence knows nothing of the particular other essences (and, by the same token, of the entities they are about). It seems clear that propositions that are essential to Socrates do not characterize what the nature of Essence is. Thus, appeal to the essence of Essence is presumably at odds with the plausible idea that, as Glazier explains, "the 'essentialist source' of a proposition, that in whose nature the proposition lies,

\footnotetext{
35 In fact, it might be the case that only constitutive essences can give rise to necessity, but I am not sure whether this can be conclusively established.
} 
must itself be a (Russellian) constituent of the proposition" (2017: 2887). Technically, this amounts to saying that, in the proposition ' $\mathrm{E}$ (Essence) $\mathrm{E}(x) p$ ', Essence must be a constituent of ' $\mathrm{E}(x) p$ '. Glazier thinks that since Essence is-by assumption-distinct from $x$ and not a constituent of ' $p$ ' (because ' $p$ ' is a truth about $x$ ), ' $\mathrm{E}(x) p$ ' is the claim that "some proposition not involving [E]ssence lies in the nature of something other than [E]ssence" (Ibid.). So the question remains: can ' $\mathrm{E}(x) p$ ' be true in virtue of the essence of Essence? Glazier admits that he has no proof against this claim, but that, to his knowledge, there is no plausible example of this sort.

Perhaps, there is a way to make sense of the essence of Essence proposal, but I will not try to give a definitive answer on that matter here. Rather, for the sake of the argument I will assume that both ' $\mathrm{E}(x) p$ ' and its necessity can be explained by the constitutive essence of some entity, $\pi$, in order to see whether this strategy can be of any help. Thus, if you are happy with Essence, then just read the following arguments as involving Essence. ${ }^{36}$

Consider ' $\mathrm{E}(\pi) \mathrm{E}(x) p$ ': given NE, it must be necessary. In order to uphold Source, essentialists face two possibilities: either ' $\square \mathrm{E}(\pi) \mathrm{E}(x) p$ ' is explained by an iterated essence with bearer identity or by an iterated essence without bearer identity-i.e., either by ' $\mathrm{E}(\pi) \mathrm{E}(\pi) \mathrm{E}(x) p$ ' or ' $\mathrm{E}(z) \mathrm{E}(\pi) \mathrm{E}(x) p$ '. Opting for the latter forces essentialists to investigate further away from $x$ and $\pi$, and I have honestly no idea what $z$ could even stand for at this point. Other things being equal, an infinite regress ensues because the question now switches to which entity is such that facts about its essence can explain the necessity of ' $\mathrm{E}(z) \mathrm{E}(\pi) \mathrm{E}(x) p$ ', and so on. With respect to the former option, essentialists unsurprisingly arrive at a structure similar to S1:

\section{Structure 2 (S2)}

(h) $[\mathrm{E}(\pi) \ldots \mathrm{E}(x) p]<(\mathrm{g})[\square \mathrm{E}(\pi) \ldots \mathrm{E}(x) p]$;

(f) $[\mathrm{E}(\pi) \mathrm{E}(\pi) \mathrm{E}(\pi) \mathrm{E}(x) p]<(\mathrm{e})[\square \mathrm{E}(\pi) \mathrm{E}(\pi) \mathrm{E}(x) p]$;

(d) $[\mathrm{E}(\pi) \mathrm{E}(\pi) \mathrm{E}(x) p]<(\mathrm{c})[\square \mathrm{E}(\pi) \mathrm{E}(x) p]$;

(b) $[\mathrm{E}(\pi) \mathrm{E}(x) p]<(\mathrm{a})[\square \mathrm{E}(x) p]$, (a') $[\mathrm{E}(x) p]$.

In $\mathbf{S 2}$, there is an explanation of both ' $\square \mathrm{E}(x) p$ ' and ' $\mathrm{E}(x) p$ ' in terms of ' $\mathrm{E}(\pi) \mathrm{E}(x) p$ ': (a) and (a') are explained by (b). Such schematic explanations can be considered as unproblematic since they are arguably valid instances of NT: if $[\mathrm{E}(\pi) \mathrm{E}(x) p]<[\square \mathrm{E}$ $(x) p]$, then $[\mathrm{E}(\pi) \mathrm{E}(x) p]<[\mathrm{E}(x) p]$. As a matter of fact, they mirror how ' $\mathrm{E}(x) p$ ' explains both the truth and the necessity of its prejacent in S1: ' $\square p$ ' and ' $p$ ' because ' $\mathrm{E}(x) p{ }^{\prime} \cdot{ }^{37}$

However, difficulties arise at the level of ' $\mathrm{E}(\pi) \mathrm{E}(x) p$ ' and here essentialists face another two options. The first one is to say that, just as $\mathbf{S 1}, \mathbf{S 2}$ is composed of one

\footnotetext{
${ }^{36}$ Other candidate entities can be God or, one idea I am sympathetic to, Leibniz's best of all possible worlds. If we can truly say that the best of all possible worlds is essentially such that Socrates is human, that Plato is human, etc., then this could be used as a counterexample to the constituency and ultimacy constraints highlighted by Glazier for his essentialist explanation. However, we should make sure that when we say that the best of all possible worlds is essentially such that Socrates is human, it is the constitutive notion of essence that is at stake, and not some other essentialist notion.

37 Note, however, that Glazier's essentialist explanation cannot hold in this specific context since if ' $\mathrm{E}(x)$ $p$ ' explains ' $p$ ', there can be no essentialist explanation of ' $\mathrm{E}(x) p$ ' in terms of ' $\mathrm{E}(\pi) \mathrm{E}(x) p$ '.
} 
constitutive essence, ' $\mathrm{E}(\pi) \mathrm{E}(x) p$ ', and an infinity of iterated consequential essences above it-i.e., ' $\mathrm{E}(\pi)(\mathrm{E}(\pi) \mathrm{E}(x) p)$ ', etc. If this is the option endorsed, then the exact same structural problems as the ones encountered with $\mathbf{S 1}$ resurface. This is so because, given NT, violations of asymmetry and irreflexivity ensue: $[\mathrm{E}(\pi) \mathrm{E}(x) p]<$ $[\mathrm{E}(\pi)(\mathrm{E}(\pi) \mathrm{E}(x) p],[\mathrm{E}(\pi)(\mathrm{E}(\pi) \mathrm{E}(x) p]<\square[\mathrm{E}(\pi) \mathrm{E}(x) p]$, and then, by $\mathbf{N T},[\mathrm{E}(\pi)(\mathrm{E}(\pi) \mathrm{E}(x)$ $p]<[\mathrm{E}(\pi) \mathrm{E}(x) p]$, contradiction.

The second option is to confer the same metaphysical status to all claims about the essence of $\pi$ (i.e., all claims of the form ' $\mathrm{E}(\pi) \mathrm{E} .$. '), and to say that they are of the constitutive kind. Perhaps this is more plausible than saying that iterated essences in $\mathbf{S 1}$ are constitutive, because truths about the essence of $\pi$-depending of what ' $\pi$ ' actually refers to-might be said to characterize directly what $\pi$ is, and nothing else. I acknowledge that this becomes a rather thorny matter, and we sink into ever deeper levels. But, to cut short, we saw what kind of problems arise if there is an upwards or downwards chains of explanations in such structures. Presumably then, no truth about the essence of $\pi$ would be explained in terms of the essence of $\pi$ if this second option is endorsed. This means that there can be no true instance of NT, because if $[\mathrm{E}(\pi) \mathrm{E}(\pi) \mathrm{E}(x) p]<[\square \mathrm{E}(\pi) \mathrm{E}(x) p]$, then NT tells us that $[\mathrm{E}(\pi) \mathrm{E}(\pi) \mathrm{E}(x)$ $p]<[\mathrm{E}(\pi) \mathrm{E}(x) p]$. However, with what has just been said, it is not the case that $[\mathrm{E}(\pi) \mathrm{E}$ $(\pi) \mathrm{E}(x) p]<[\mathrm{E}(\pi) \mathrm{E}(x) p]$. Therefore, by modus tollens, it is not the case that $[\mathrm{E}(\pi) \mathrm{E}(\pi)$ $\mathrm{E}(x) p]<[\square(\mathrm{E}(\pi) \mathrm{E}(x) p]$.

So, explaining the necessity of ' $\mathrm{E}(x) p$ ' in terms of ' $\mathrm{E}(\pi) \mathrm{E}(x) p$ ' can only partially solve the problems that essentialists face. For, they now have to explain the necessity of ' $\mathrm{E}(\pi) \mathrm{E}(x) p$ ' and, even if we assume that there is a candidate-entity that stands for ' $\pi$ ', none of the options I have outlined in this section seems promising or successful.

\section{Concluding remarks}

Our discussion so far shows that there is no straightforward way for essentialists to account for the necessity of essences. On the one hand, if they appeal to an iterated essence with bearer identity to explain the necessity of ' $\mathrm{E}(x) p$ ', a structure like $\mathbf{S 1}$ arises. Prima facie, such a structure is benign, but once plausible assumptions and principles are taken on board, violations of asymmetry and irreflexivity ensue, and there is no obvious way out. If, on the other hand, essentialists appeal to an iterated essence without bearer identity to explain the necessity of ' $\mathrm{E}(x) p$ ', a structure like $\mathbf{S 2}$ is generated and their first challenge is to find which entity-if any-is such that it is essential to it that ' $\mathrm{E}(x) p$ '. The problem is that even if we assume, for the sake of the argument, that there is such an entity, essentialists merely transfer the initial difficulty of explaining ' $\square \mathrm{E}(x) p$ ' to that of explaining ' $\square \mathrm{E}(y) \mathrm{E}(x) p$ ': either the explanans is an iterated essence with bearer identity or it is an iterated essence without bearer identity. The former option leads to vicious circularities while the latter forces essentialist to find another entity, thereby moving the same dilemma to a further level, and so on. Since there is no straightforward way out of these issues, it seems to me that Source should be restricted to constitutive essences only, and that a different account of the necessity of such essences is needed. 
This might be done by saying that essences explain their own necessity. Of course, this means that NT can no longer hold, because otherwise essences will eventually explain themselves: if $[\mathrm{E}(x) p]<[\square \mathrm{E}(x) p]$, then $[\mathrm{E}(x) p]<[\mathrm{E}(x) p] .{ }^{38}$ In response, essentialist could try to argue that if an essence explains its necessity, then that essence does not need to make itself true, because its truth is already given/ established. However, the difficulties I have raised in Sect. 3 will have to be considered: if it is indeed true that essences simpliciter lack any explanatory power to bring forth necessity, then on this view essences would not only lack the power to explain their own necessity, but also the power to explain other necessities. Consequently, the strategy advocated by Wallner and Vaidya will not be available.

With all what has been said, one solution consists in considering the necessity of essences as brute, which corresponds to Hale's own conclusion on the matter (2013: 158):

The point of the essentialist theory is [...] to locate a base class of necessities - those which directly reflect the nature of things-in terms of which the remainder may be explained. The kind of explanation it offers, then, is [...] one which exhibits the class of necessities as structured in a certain way, by identifying some necessities as basic or fundamental, and the rest as dependent, inheriting their necessity, ultimately, from necessities in the base class.

All the aforementioned difficulties I have identified are blocked on this view, and the only modification that needs to be done consists in the following restriction on Source: for every non-essential truth $p$, if $p$ is necessary, then $p$ is necessary because there is something the nature of which is such that $p$. Moreover, essentialists can still rely on the necessity of essences to try to address the 'gap'-problem if needed. However, restricting Source in such a way comes at the price of rendering essentialism significantly less attractive, since it is no longer a theory of the source of necessity, but merely a theoretical framework that explains some necessities. To conclude, the difficulties I have identified in this paper should be addressed if essentialists want to defend what I take to be the central tenet of their theory.

Acknowledgements Heartfelt thanks go to my supervisors Thomas Sattig and Tobias Wilsch for their helpful comments. I am particularly indebted to two anonymous reviewers for Philosophical Studies for reports which helped to improve the present inquiry considerably. I would also like to thank Riccardo Baratella, Hagen Braun, Christina Conroy, Fabrice Correia, Joaquim Giannotti, Richard Glauser, Martin Glazier, Vincent Grandjean, Kathrin Koslicki, Olivier Massin, Alex Skiles, Michi Wallner, Nathan Wildman, and audiences at Tübingen University's 'Oberseminar in Theoretische Philosophie' and Neuchâtel University's 'Colloque de Recherches' for their insights, suggestions and comments.

Funding Open Access funding enabled and organized by Projekt DEAL. Deutsche Forschungsgemeinschaft (DFG)_Projektnummer 394341335, Quellen der Notwendigkeit/Sources of Necessity.

Open Access This article is licensed under a Creative Commons Attribution 4.0 International License, which permits use, sharing, adaptation, distribution and reproduction in any medium or format, as long as

\footnotetext{
38 Similarly, NT* will not do: if $[\mathrm{E}(x) p]<[\square \mathrm{E}(x) p] \& \neg[\mathrm{E}(x) p]<[\mathrm{E}(x) p]$, then $[\mathrm{E}(x) p]<[\mathrm{E}(x) p]$. Contradiction.
} 
you give appropriate credit to the original author(s) and the source, provide a link to the Creative Commons licence, and indicate if changes were made. The images or other third party material in this article are included in the article's Creative Commons licence, unless indicated otherwise in a credit line to the material. If material is not included in the article's Creative Commons licence and your intended use is not permitted by statutory regulation or exceeds the permitted use, you will need to obtain permission directly from the copyright holder. To view a copy of this licence, visit http:// creativecommons.org/licenses/by/4.0/.

\section{References}

Blackburn, S. (Ed.). (1986). Morals and modals. In Essays in quasi-realism (pp. 52-74). Oxford: Oxford University Press.

Bliss, R. L. (2013). Viciousness and the structure of reality. Philosophical Studies, 166(2), 399-418.

Casullo, A. (2020). Essence and explanation. Metaphysics, 2, 88-96.

Correia, F. (2012). On the reduction of necessity to essence. Philosophy and Phenomenological Research, 84(3), 639-653.

Correia, F., \& Skiles, A. (2019). Grounding, essence, and identity. Philosophy and Phenomenological Research, 98(3), 642-670.

Correia, F., \& Skiles, A. (2020). Essence, modality, and identity. (Unpublished Manuscript).

Dasgupta, S. (2014). The possibility of physicalism. The Journal of Philosophy, 111(9/10), 557-592.

Ditter, A. (2020). The reduction of necessity to essence. Mind, 129(514), 351-380.

Fine, K. (1994). Essence and modality. Philosophical Perspectives, 8, 1-16.

Glazier, M. (2017). Essentialist explanation. Philosophical Studies, 174(11), 2871-2889.

Hale, B. (2013). Necessary beings: An essay on ontology, modality, and the relations between them. Oxford University Press.

Hale, B. (2018). The basis of necessity and possibility. Royal Institute of Philosophy Supplements, 82, $109-138$.

Leech, J. (2020). From essence to necessity via identity. Forthcoming in Mind. https://doi.org/10.1093/ $\mathrm{mind} / \mathrm{fzaa0} 12$

Lowe, E. J. (2008). Two notions of being: Entity and essence. Royal Institute of Philosophy Supplements, $62,23-48$.

Lowe, E. J. (2012). Essence and ontology. In L. Novak, D. D. Novotny, P. Sousedik, \& D. Svoboda (Eds.), Metaphysics: Aristotelian, scholastic, analytic (pp. 93-111). De Gruyter.

Mackie, P. (2020). Can metaphysical modality be based in essence? In M. Dumitru (Ed.), Metaphysics, meaning, and modality: themes from kit fine (pp. 247-264). Oxford University Press.

Maurin, A. S. (2019). Grounding and metaphysical explanation: It's complicated. Philosophical Studies, 176(6), 1573-1594.

Noonan, H. (2019). The new aristotelian essentialists. Metaphysica, 19, 87-93.

Rabin, G. O., \& Rabern, B. (2016). Well founding grounding grounding. Journal of Philosophical Logic, 45, 349-379.

Romero, C. (2019). Modality is not explainable by essence. Philosophical Quarterly, 69, 121-141.

Rosen, G. (2010). Metaphysical dependence: Grounding and reduction. In B. Hale \& A. Hoffman (Eds.), Modality: Metaphysics, logic, and epistemology (pp. 109-136). Oxford: Oxford University Press.

Teitel, T. (2019). Contingent existence and the reduction of modality to essence. Mind, 128(509), 39-68.

Van Cleve, J. (1999). Problems from Kant. Oxford University Press.

Van Cleve, J. (2018). Brute necessity. Philosophy Compass, 13(9), 1-43.

Vogt, L. (2020). Two Problems for Justin Zylstra's Truthmaker Semantics for Essence. Inquiry.

Wallner, M. (2019). The structure of essentialist explanations of necessity. Thought: A Journal of Philosophy, 9(1), 4-13.

Wallner, M., \& Vaidya, A. (2020). Essence, explanation, and modality. Philosophy, 95(4), 419-445.

Werner, J. (2020). Contingent objects, contingent propositions, and essentialism. Mind, 130(520), 12831294. 
Wildman, N. (2018). On shaky ground? Exploring the contingent fundamentality thesis. In R. Bliss \& G. Priest (Eds.), Reality and its structure: Essays on fundamentality (pp. 275-290). Oxford: Oxford University Press.

Wildman, N. (2021). Against the reduction of modality to essence. Synthese, 198(6), 1455-1471.

Zylstra, J. (2019). Making semantics for essence. Inquiry, 62(8), 859-876.

Publisher's Note Springer Nature remains neutral with regard to jurisdictional claims in published maps and institutional affiliations. 